\section{Normal iconic memory for stimuli invisible to the rods}

WILLIAM P. BANKS

Pomona College, Claremont, California 91711

and

\section{GRAYSON BARBER \\ Princeton University, Princeton, New Jersey 08540}

This note is prompted in part by the unsettling report of Mollon and Polden (1978) on the time constants of tachistoscopes. They tested a number of tachistoscopes, including an Iconix fitted with the lamps used by Banks and Barber (1977), and found that they typically required about $18 \mathrm{msec}$ to reach $90 \%$ of full output when they were turned on or to decline to $10 \%$ of output when turned off. Furthermore, the spectral composition of the light changed over the rise and fall periods. The change in spectral composition is particularly important because the conclusion we drew (Banks \& Barber, 1977), that iconic memory was not strictly a rod phenomenon, depended in part on use of stimuli that present zero contrast to the rods, despite being clearly distinguishable to the cones. In that research we created letter arrays by using one color of paper for figure and another for ground such that the cones, but not the rods, could see the contrast between the colors and thus only the cones could be used to detect the letters. The fact that these arrays gave typical iconic decay curves and a partial report superiority seemed to us to be good evidence that iconic memory did not require the rods.

We realized, of course, that the matching of the colored papers depends on the spectral composition of the illuminant, and we made our matches using as an illuminant the steady-state light of the stimulus field of the Iconix, filtered through the two mirrors through which the stimulus was seen in our experiments. If, however, the spectral composition of the light during the rise and fall periods of the tachistoscope lamps was not the same as it was during the steady-state period, then the stimulus arrays would not have zero contrast for the rods during these periods, and the rods might have been able to mediate iconic memory during experimental trials.

Another motivation for this note comes from Sakitt and Long (1979), which shows that a small

This research was supported by NIH Grant 1 R01 MH33279-01 and by NSF Grant 78-17442. Requests for reprints should be sent to William P. Banks, Department of Psychology, Pomona College, Claremont, California 91711. deviation from zero scotopic contrast can allow the rods to perceive a figure-ground contrast. This finding of Sakitt and Long was intended as an argument against our original conclusions, since it is virtually impossible to make an absolutely perfect scotopic match with the limited set of colored papers available. Now, however, any such argument has much more force, since the change in spectral composition of the lamps during their rise and fall periods can be expected to disturb the scotopic matching of most of the stimuli.

Clearly, then, the change in spectral composition of the illuminant over the period of the tachistoscopic presentation casts doubt on one source of evidence against the hypothesis that the rods mediate iconic memory under the photopic conditions typical of iconic memory experiments. Despite the other evidence against a rod locus of iconic memory, it is unfortunate that the demonstration of iconic memory with zero scotopic contrast is in question, since this is a particularly compelling piece of evidence. As Mollon and Polden say (1978, p. 565), "This crucial test of Sakitt's hypothesis remains to be performed properly."

There are several strategies one could take to reestablish the validity of this crucial test of the rod hypothesis. The obvious one would be to replicate the Banks and Barber experiments exactly, but with apparatus that did not create color changes over the course of the presentation. Such apparatus might be a tachistoscope fitted with the $\mathrm{ED}_{3}$ lamps mentioned by Mollon and Polden or a projection tachistoscope in which a shutter, which would not introduce color changes during rise and fall periods, controlled stimulus presentation. A replication of this sort would still not answer the argument of Sakitt and Long that very small deviations from zero scotopic contrast can, in some situations, lead to scotopic visibility. No matter how well the figure and ground colors were matched scotopically, the question of whether any small deviation from perfection created scotopic discriminability could still be raised.

Because of these difficulties with what might seem to be the most straightforward experimental strategy, it seemed better to pursue another approach to the question. Instead of replicating the original experiment, we conducted some investigations to determine whether the stimuli we used were effectively invisible scotopically despite the changes in the color of the illuminant over the presentation interval. Even though the rise and fall periods occupied over $50 \%$ of the total presentation of a nominal $50 \mathrm{msec}$, the mean light intensity is not as great then as during the steady-state period, and the effective summed 
deviation from scotopic matching may not have been sufficient to allow discrimination for the rods. As Adelson (1979) has shown, small deviations from perfect scotopic matching do not necessarily render iconic displays visible to the rods.

Two studies verifying the scotopic invisibility of our original stimuli under tachistoscopic presentation are reported here. In the first, it is shown that these stimuli are ineffective for iconic memory in a rod monochromat, who nevertheless does show typical iconic storage with black letters. In the second study, it is shown that these stimuli are also ineffective for iconic memory for dark-adapted subjects with normal vision.

\section{EXPERIMENT 1}

\begin{abstract}
Method
Subject. The rod monochromat, who will be known as R.M. in this report, is a highly intelligent male undergraduate, aged 19 years at the time of the study. Despite the handicaps imposed by his visual problem (poor acuity, day blindness, total color blindness, and exaggerated nystagmus), he performs well as a student and seems to suffer no restriction in other aspects of his life. R.M. has been the subject of treatment and examination by ophthalmologists since early childhood. He has been fitted with dark lenses that have a slight correction for astigmatism. Wearing the glasses, he has approximately $20 / 200$ vision as tested
\end{abstract} by a Snellen eye chart. He is totally lacking color vision.

Procedure. There were two types of stimuli: black letters and the "color test" cards (those containing scotopically indistinguishable letters) used by Banks and Barber (1977). Both types had an array of three rows of four letters. The black-letter stimuli were drawn in black marking pen on white cardstock. These letters were approximately $1 \mathrm{deg}$ wide $\times 1.3 \mathrm{deg}$ high, were separated from each other by about $.7 \mathrm{deg}$ horizontally and $1.3 \mathrm{deg}$ vertically, and were drawn with a stroke width of .2 deg. The "color test" stimuli from Banks and Barber are designed to have zero contrast for the rods and are described on pages $537-538$ of their article. They are approximately $32 \mathrm{~min}$ high $\times 19 \mathrm{~min}$ wide.

R.M. viewed these cards at $87 \mathrm{~cm}$ in an Iconix tachistoscope with a pair of Sylvania F6T5/CW (cool white) lamps in each field. (These are the same type of lamp used by Banks \& Barber, 1977.) At the start of each trial, the experimenter struck a telegraph key; 500 msec later, the stimulus field was presented, always for $50 \mathrm{msec}$. (A fixation field of the same luminance as the stimulus field was seen whenever the stimulus was not in view.) $\mathrm{A} 2,500-, 400-$, or $100-\mathrm{Hz}$ tone served as a clue to specify whether the subject was to report the top, middle, or bottom row, respectively. Cues were presented $0,100,250,500$, or $1,000 \mathrm{msec}$ after the stimulus field terminated. Interspersed with the cued partial-report trials were whole-report trials on which R.M. had to report as many letters as he could. He had 12 trials for every combination of cue delay and row for the blackletter stimuli (making a total of 180 trials for them). Because he was never able to report a single letter correctly from the scotopically indistinguishable arrays, and because he experienced discouragement on these trials that we feared might detract from his efforts on the black letters, we did not present him with the full set of trials that was used for the black letters. We did give at least one whole-report and one partial-report for each of the scotopically indistinguishable stimuli.

Both the stimulus and the fixation fields had a luminance of 17 fL (photopic weighting). R.M. viewed all tachistoscopic stimuli through his dark glasses, which reduced the tachistoscope's luminance to $.0085 \mathrm{fL}$ by scotopic weighting. It was necessary to have him wear the dark glasses because his "day blindness" prevented his seeing anything at the standard luminance of the tachistoscope.

\section{Results and Discussion}

Figure 1 shows estimated number of letters available as a function of delay of readout cue for R.M. As can be seen, he has no visual memory at all for the stimuli that Banks and Barber assumed were invisible to the rods. It seems clear, therefore, that the potential problem with our crucial experiment was not a real one. The change in the spectrum of the fluorescent tubes over their rise and fall times did not make the stimuli scotopically visible, and the conclusion that iconic memory for these stimuli cannot be mediated by the rods stands.

Also shown in Figure 1 are R.M.'s partial-report and whole-report data for the large black letters. This set of data shows a decline in accuracy of partial report over the delay interval and an initial superiority of partial over whole report. This iconic memory function demonstrates that R.M.'s failure to show any visual memory for our scotopically indistinguishable stimuli results, not from a lack of iconic memory, but from the scotopic indistinguishability of the letters.

We considered the possibility that the brief presentation and dim illumination, or the combination of the two, might have been the critical factors preventing R.M.'s rods from seeing the stimulus letters. After all, the rods of the normally endowed eyes of our subjects in the previous studies (Banks \& Barber, 1977) did not have to view the stimuli through attenuating eyeglass lenses. We therefore

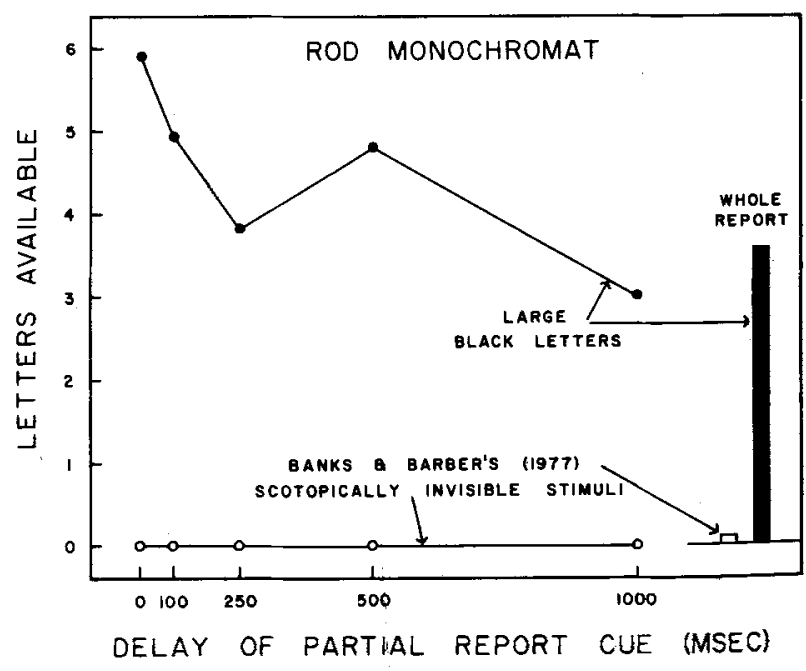

Figure 1. Whole and partial report of a briefly presented array by a rod monochromat. The total lack of visual memory for the scotopically invisible stimuli indicates that the rods can not carry iconic memory for these stimuli and thus that the iconic memory Banks and Barber (1977) obtained for these could not have involved the rods. The function for the large black letters shows that this subject is capable of iconic storage and that the lack of iconic memory for the other stimuli does not reflect merely a general lack of iconic memory. 
showed the scotopically matched stimuli to R.M. both with $100-\mathrm{msec}$ presentations and with continuous illumination in the tachistoscope, both with and without his dark glasses. We asked him to report as many letters as he could. In no case was he able to report a single letter correctly. Furthermore, he reported that the tachistoscope was blindingly bright without his dark glasses and that he could see nothing at all in it. The fact that the tachistoscope at this luminance was able to induce R.M.'s day blindness (presumably rod saturation) is significant because, if his rods are like those of normals, we can conclude that no one's rods would be able to function under the conditions typical of iconic memory experiments.

\section{EXPERIMENT 2}

This experiment seeks to verify that normal trichromats, when dark adapted, cannot see our scotopically indistinguishable stimuli under transient illumination from the tachistoscope. The studies in question in Banks and Barber (1977) used normal trichromats, and we cannot be perfectly certain that R.M.'s rods behave exactly like those of normals.

\section{Method}

Three normal trichromats were dark adapted and tested with the scotopically indistinguishable stimuli used by Banks and Barber (1977). These subjects were females from 18 to 21 years of age. All had normal color vision as tested by Ishihara pseudoisochromatic color plates. One had visual acuity of $20 / 10$, as measured by the Snellen chart, one had her vision corrected to $20 / 20$ with glasses she wore throughout the study, and one had uncorrected $20 / 30$ vision.

The entire study took place in the same room with the same Iconix tachistoscope used by Banks and Barber (1977). Before any tests were conducted, the subjects were in the darkened room for $15 \mathrm{~min}$, and most of the tests took place after $30 \mathrm{~min}$ of dark adaptation. Our criterion for scotopic vision was absence of color sensation and a central blind spot in the visual field. Room illumination and conditions were approximately the same as was reported in the test of the scotopic equivalence of the colors used for the scotopically indistinguishable stimuli (Banks \& Barber, 1977, p. 538). In the present study, the stimuli were viewed in the stimulus field of the tachistoscope, with a $.1 \%$ transmitting Wratten neutral density filter inserted in the optical path. An additional $25 \%$ transmitting Wratten neutral density filter was inserted on some trials, and the light output of the lamps was adjusted electronically on some trials. ${ }^{1}$ The luminance of the tachistoscope was electronically varied from 1.3 to $17 \mathrm{fL}$ over the experiment, and the Wratten filters multiplied these luminances by either $10^{-3}$ or $2.5 \times 10^{-4}$, depending on whether both or only the one was in the optical path.

The initial plan of the study was to replicate the two experiments that we had previously performed under photopic conditions (Experiments 1 and 2 of Banks \& Barber, 1977) with the dark-adapted eye. These experiments used the previously discussed scotopically indistinguishable letters as stimuli, as well as color patches (a 3 by 4 array of colored rectangles of various easily discriminable hues that were chosen such that all were the same lightness scotopically), and black letters ( $32 \mathrm{~min}$ high and 19 min wide, with a stroke width of $4 \mathrm{~min}$, drawn to match the scotopically invisible letters in size). However, none of the subjects was able to report any of the letters under either partial-report or whole-report instructions with either set of stimulus conditions we had used (50-msec stimulus with bright pre- and poststimulus fields in our 1977 Experiment 1 and 100-msec stimulus with dark pre- and poststimulus fields in Experiment 2). In fact, we could find no stimulus duration and no combination of light and dark pre- and poststimulus fields at which any of the subjects could make out any letters at all on the scotopically matched cards, and it was very difficult for all but the subject with $20 / 10$ vision to read the black letters. In these attempts, we varied the luminance over the available range (see above) to make sure our finding of no. visibility was not specific to any particular luminance level. In no case, however, did we raise the luminance above the point at which color was seen. It is possible that the stimuli would have been seen with brighter fields, but with these subjects we could not be sure that the cones were not doing the seeing once photopic levels were reached.

There was no point in continuing to test for iconic memory with these stimuli, and we set up another stimulus condition intended to include some proportion of the rise and fall periods in a quasi-steady-state illumination of the stimuli by the tachistoscope. In this study, the tachistoscope was set to switch back and forth between fields 1 and 2 under the control of a squarewave oscillator. The maximum rate of switching possible with this system was $500 \mathrm{~Hz}$; this rate created a cycle in which each field was powered for only $1 \mathrm{msec}$ at a time. As the rate of switching was lowered from $500 \mathrm{~Hz}$ to a very slow rate, the effective illuminant varied in its constitution. At the $100-\mathrm{Hz}$ rate, the ratio of rise and fall periods to the duration of steady-state illumination should match that of a 50-msec exposure, and at the $50-\mathrm{Hz}$ rate, it should match the ratio found in a $100-\mathrm{msec}$ exposure. By moving a white object, or by moving the eyes as Mollon and Polden suggest, in the flickering light, it was possible to see the temporal changes spread out spatially. Thus viewed, at all rates below $100 \mathrm{~Hz}$ the output of the tubes showed the yellow rise and fall periods noted by Mollon and Polden, as well as steady-state white on-periods and black off-periods.

All stimuli, including the black letters, were presented to the subjects at a wide variety of switching rates. Included among the stimuli tested were the color patch stimuli Banks and Barber used (1977, Experiments 1 and 2), the scotopically invisible ("color test") letters, the black letters drawn to match these in size, the larger black letters used to obtain an iconic decay curve with R.M. in Experiment 1, and letter arrays typed in IBM elite upper case.

\section{Results and Discussion}

At no rate of switching and at no scotopic level of luminance was any subject able to read even one letter from the scotopically indistinguishable stimuli, and the color patch stimuli appeared a uniform shade of gray at all flashing rates. The subjects had no trouble reading the large black letter stimuli used with R.M., but only the subject with $20 / 10$ vision could read any of the black letters that were of the same size and stroke thickness as the scotopically invisible letters. However, she could do so only under conditions of continuous viewing, and not with brief presentations. $^{2}$

This study establishes a point that we previously offered as a suggestion, namely that rod acuity is so poor that rods could not distinguish the stimuli used in most iconic memory experiments, much less mediate iconic memory for them (cf. Banks \& Barber, 1977, pp. 542-543). Our dark-adapted subjects could not even see the uppercase IBM elite letters under scotopic illumination levels in the tachistoscope, and 
they could hardly see the black letters drawn to be the same size as the scotopically indistinguishable stimuli. Even if we had not matched our supposedly scotopically indistinguishable colors adequately, the rods would still not have been able to see them.

In sum, this experiment supports the conclusion drawn from Experiment 1 that the rods cannot see the letters in the "color test" stimuli we used in Banks and Barber (1977), although the invisibility of the letters may result as much from poor rod acuity as from adequate scotopic matching of colors. With stimuli of the size we used, the figure-ground contrast would have to be very good to render them visible to the rods. Whatever slight mismatch in scotopic greys the transient change in illuminant during the tachistoscopic rise and fall periods may have created was not adequate to render the letters visible to the rods. Since these very same stimuli did give iconic memory functions in Banks and Barber (1977), the conclusion that rods are not necessary for iconic storage still stands.

In the course of this study, we made several additional observations that cast doubt on a rod locus of iconic memory. First, when looking into our Iconix tachistoscope at brightness settings in the range used for iconic memory experiments, R.M. was unable to see anything without his dark glasses because the stimuli were bright. If R.M.'s rods behave like those of normal trichromats, it seems unlikely that normal iconic memory at photopic levels could be mediated by the rods. With bright pre- and poststimulus fields, the rods of normal viewers would be in a state of continuous saturation, as R.M.'s were, and, even with a dark poststimulus field, the recovery of the rods from saturation would take longer than the duration of storage usually attributed to iconic memory.

A second observation was that rod acuity seems poor enough to eliminate the rods as possible mediators of iconic memory in perhaps the majority of studies. Examination of about a dozen published studies of iconic memory indicates that letters subtending from .2 to .5 deg yield reliable iconic decay functions and partial-report superiority over whole report. Our black-letter stimuli, which subtended roughtly $1 / 2 \times 1 / 3 \mathrm{deg}$, were barely discernible to the dark-adapted eye with continuous viewing under scotopic conditions, and they could not be seen at all when presented in a $50-$ or $100-\mathrm{msec}$ flash. Sakitt has concluded that the rod icon is longer lasting and more robust than the cone icon and that "sparing" the rod component would "spoil" the icon (Sakitt \& Long, 1979; cf. also Sakitt, 1976, and Sakitt \& Long, 1978). However, her conclusions can hold only for the relatively large stimuli and conditions of dark adaptation she has used. $\mathbf{A}$ long and robust rod component would make no usable contribution to iconic memory in most situations because the stimuli are too small for the rods to discriminate in the first place.

In conclusion, we note that the "crucial experiment" of Banks and Barber still stands. Our findings are similar to those of Adelson (1979), in that small discrepancies from perfect scotopic matching of figure and ground do not suffice to make the stimuli visible to the rods. Clearly, iconic memory exists for stimuli the rods cannot discriminate. In addition, we suggest that the stimuli of perhaps a majority of iconic memory experiments are too small and too bright for the rods to see. Thus, iconic memory for scotopically invisible stimuli may be the rule rather than an exceptional finding that depends on carefully constructed stimuli.

\section{REFERENCES}

Adelson, E. H. Visual persistence without the rods. Perception \& Psychophysics, 1979, 26, 254-256.

BanKs, W. P., \& Barber, G. Color information in iconic memory. Psychological Review, 1977, 84, 536-546.

Mollon, J. D., \& Polden, P. G. On the time constants of tachistoscopes. Quarterly Journal of Experimental Psychology, $1978,30,553-568$.

SakitT, B. Iconic memory. Psychological Review, 1976, 83, 257-276.

SakitT, B., \& Long, G. M. Relative rod and cone contributions in iconic storage. Perception \& Psychophysics, 1978, 23, 527-536.

SakitT, B., \& Long, G. M. Spare the rod and spoil the icon. Journal of Experimental Psychology: Human Perception and Performance, 1979, 5, 19-30.

\section{NOTES}

1. The luminance was varied electronically to test whether the varying supply voltages would affect the color or duration of the rise and fall periods of the lamps. If the color was affected, it did not suffice to unmatch the scotopically matched colors.

2. The first author (W.P.B.) repeated all of the operations of Experiment 2 on himself as a subject in a single 3-h session and verified the results from the session obtained with the three normal trichromats. The visibility of the smaller black letters under scotopic conditions and with complete dark adaptation was of particular interest. At a luminance of $4 \times 10^{-3} \mathrm{fL}$ and a 100-msec exposure duration, these letters looked like dim smudges on the cards, even though W.P.B.'s vision is $20 / 12$. With continuous viewing and slightly greater light intensity (the luminance of the tachistoscope lamps was adjusted electronically to a point just below that at which color was visible), some features of the letters could be seen and some of their identities guessed, but the letters could still not be identified with tachistoscopic presentation at this luminance. The central scotopic scotoma was clearly visible with flickering or tachistoscopic stimulation. Under these conditions it had a diameter of about $45 \mathrm{~min}$, completely covering one, and sometimes two, of the small black letters. As we have previously observed (Banks \& Barber, 1977, pp. 542-543), iconic memory should have position effects that reflect the rod acuity function if rods carry iconic memory. These observations indicate that the central scotoma should also, for most observers, result in very poor performance for the central $1 / 2-1$ deg of the field. In fact, performance for the central items is relatively good in iconic memory experiments.

(Received for publication December 6, 1979; revision accepted March 24, 1980.) 